\title{
Shifts in Protein Charge State Distributions with Varying Redox Reagents in Nanoelectrospray Triple Quadrupole Mass Spectrometry
}

\author{
Cheng Zhao, Troy D. Wood, ${ }^{*+}$ and Stanley Bruckenstein \\ Department of Chemistry, University at Buffalo, State University of New York, Buffalo, New York, USA
}

The influence of a number of redox reagents on the charge state distribution in nanoelectrospray mass spectrometry was examined using cytochrome $c$ and ubiquitin. The redox active species investigated were: 1,4-benzoquinone, quinhydrone, tetracyanoquinodimethane (TCNQ), hydroquinone, and ascorbic acid. The redox active species was mixed with the protein sample before injection into the nanoelectrospray emitter, and mass spectra were acquired using a triple quadrupole mass spectrometer. Under the same experimental conditions, the charge state distribution of cytochrome $c$ was observed to shift from a weighted average charge state of 14.25 (in the absence of redox species) to 7.10 in the presence of 1,4-benzoquinone. When quinhydrone was mixed with cytochrome $c$, the charge state distribution of the protein also shifted to lower charge states (weighted average charge state $=$ 9.43), indicative of less charge state reduction for quinhydrone than with 1,4-benzoquinone. Addition of the redox reagent had little effect on the conformation of cytochrome $c$, as indicated by far ultraviolet circular dichroism spectra. In contrast, the reagents TCNQ, hydroquinone, and ascorbic acid exhibited negligible effects on the observed charge state distribution of the protein. The differing results for these redox reagents can be rationalized in terms of the redox half reactions involving these species. The results observed with ubiquitin upon adding quinhydrone were analogous to those observed with cytochrome $c$. (J Am Soc Mass Spectrom 2005, 16, 409-416) (c) 2004 American Society for Mass Spectrometry

$\mathrm{T}$ lechnological advances in the field of mass spectrometry are dramatically advancing biological research, especially in the field of proteomics $[1,2]$. Electrospray ionization (ESI) [3] is one of the most important of these proteomic tools. In ESI, multiply charged ions of biomolecules are formed, which enables observation of macromolecules at relatively low $\mathrm{m} / \mathrm{z}$ values. This allows the use of conventional, limited $\mathrm{m} / \mathrm{z}$ range mass spectrometers such as the quadrupole mass filter to analyze samples of high molecular weights. The multiple charging phenomenon, however, also increases the complexity of the mass spectra, and may concomitantly decrease dynamic range, reduce sensitivity, and compromise mixture component analysis [4,5]. Mass spectral deconvolution procedures are frequently useful in reducing spectral complexity [6], but are decreasingly effective as the mixture complexity increases.

The charge state distributions of macromolecules can

Published online January 22, 2005

Address reprint requests to Dr. T. D. Wood, Department of Chemistry, State University of New York at Buffalo, 417 Natural Sciences Complex, Box 603000, Buffalo, NY 14260-3000, USA. E-mail: twood@acsu.buffalo.edu

* Also at the Department of Structural Biology, The State University of New York at Buffalo, Buffalo, NY.

${ }^{+}$Also at the Department of Molecular and Cellular Biophysics, Roswell Park Cancer Institute, Elm and Carlton Streets, Buffalo, NY 14263. be influenced by many factors, such as the analyte structure/conformation [7-11], analyte concentration [12-16], gas-phase reactivity [17-25], solution $\mathrm{pH}[14$, 24, 26-30], solvent composition [31-33], and various ESI instrumental parameters [18, 20, 34, 35]. Many of these factors are interrelated. For example, changes in the solution $\mathrm{pH}$, solvent, and heating conditions can alter the conformation of a protein, thereby affecting the observed charge state distribution.

Three strategies have been reported in the literature in an effort to manipulate and simplify the observed multiple charge state distributions. One condensed-phase strategy takes place by modifying the solution conditions such as $\mathrm{pH}$ [36]. A second condensed-phase strategy invoked to control the observed charge state distribution in ESI is to admix base molecules with different gas-phase basicities into the analyte mixture [37]. The other strategy takes place in the gas-phase; this has been achieved either by utilizing a post ion/ion reaction within an ion-trap spectrometer to reduce multiple charge states [19, $38-42]$, or by utilizing a "neutralization chamber" before the mass analyzer, to reduce multiple charge states [43-47]. These gas-phase approaches have demonstrated great effectiveness in reducing the ob- 
served charge state distribution of ESI; however, they require specialized instrumentation.

More recently, ESI has been miniaturized into a low-flow variant called nanoelectrospray (nanoESI), in which a stable spray is initiated by placing a nanoESI emitter in an electric field with respect to a counterelectrode inlet to the mass spectrometer; a syringe pump is not required because capillary action draws fluid to the emitter's tip [48]. Compared to conventional ESI, there are several advantages that make nanoESI very attractive: (1) the onset of ESI occurs at a lower applied voltage, which helps reduce the problem of electrical (corona) discharge; (2) because the sample flow rate is so low, there is much less sample consumption; (3) the radii of initially produced droplets are smaller, so the ionization efficiency is higher; and (4) nebulizing gas and drying gas are not necessary, so ion transmission is higher [49].

In this report, the shifts in average charge state distribution for cytochrome $c$ and ubiquitin upon addition of redox reagents were monitored by nanoESI coupled to triple quadrupole mass spectrometry. Two reagents in particular, 1,4-benzoquinone and quinhydrone, dramatically altered the charge state distribution with a shift toward lower charge states.

\section{Experimental}

\section{Sample Materials}

Acetonitrile was HPLC grade and was obtained from Aldrich. Water was prepared in a commercial mixed bed ion exchanger and filtered through a $0.2 \mu \mathrm{m}$ filter. Redox reagents used were: 7,7,8,8-tetracyanoquinodimethane (TCNQ, Aldrich, Milwaukee, WI, provided by Professor M. R. Detty), hydroquinone (Matheson, Coleman and Bell, Norwood, $\mathrm{OH}$ ), quinhydrone (Aldrich) pbenzenequinone (99\%, Sigma, St. Louis, MO), and ascorbic acid (Merck, Rahway, NJ). The redox reagent and the protein solutions were prepared in 50/50 acetonitrile/water, and were mixed together before injecting them into the nanoESI emitter with a syringe.

\section{Emitter Fabrication}

Borosilicate glass (i.d. $=0.9 \mathrm{~mm}$ or $0.69 \mathrm{~mm}$, o.d. $=1.2 \mathrm{~mm}$ ) was purchased from Sutter Instrument Co. (Novato, CA). The emitters were prepared by pulling heated glass capillaries with the Sutter Instrument Co. P-2000 laser-based micropipette puller as described previously $[50,51]$. The emitters were pulled to fine open-ended tapers ranging from 1 to $5 \mu \mathrm{m}$ and coated by polyaniline (PANI) (Monsanto, St. Louis, MO) to provide conductivity needed for nanospray [52]. Previous results have shown that pulling of borosilicate glass by a laser-based micropipette puller can result in reproducible performance by mass spectrometry for different emitters created using the same pulling program protocol [51].

\section{Circular Dichroism}

In order to determine whether or not addition of redox reagents had impact on protein conformations, circular dichroism (CD) spectra were collected. CD spectra in the far (180-260 nm) UV were determined with a JASCO J715 spectropolarimeter. Measurements were made every $0.5 \mathrm{~nm}$ using a $1.0 \mathrm{~nm}$ bandwidth and an $8 \mathrm{~s}$ time constant. Far UV spectra were measured in a $0.1 \mathrm{~cm}$ cuvette at a protein concentration of $10 \mu \mathrm{M}$, and were the average of three separate scans. All samples were in $5 \mathrm{mM}$ sodium phosphate $\mathrm{pH} 7.0$ plus the addition of the various organic components and redox agents. Measured circular dichroism ellipticity values were converted to mean residue ellipticity, [ $\theta]$, in $\operatorname{deg} \mathrm{cm}^{2}$ decimol $^{-1}$ using the equation:

$$
[\theta]=\frac{100 \Delta \theta}{C n l}
$$

where $\Delta \theta$ is the difference in millidegrees between the protein sample and the buffer sample, $C$ is the concentration of protein in $\mathrm{mM}, n$ is the number of residues in the protein, and $l$ is the path length of cuvette in $\mathrm{cm}$.

\section{Nanospray Experimental Methods}

All experiments were performed in the positive mode on a commercially available PE-SCIEX Biosystems API 3000 (Concord, Ontario, Canada) triple quadrupole mass spectrometer equipped with a homemade nanoESI source [53]. The instrument was set to Q1 scan from $300-3000 \mathrm{~m} / \mathrm{z}$ at 1.0 resolution for protein samples with a step size of $0.1 \mathrm{~m} / \mathrm{z}$, for two s. Samples (nonphysiological conditions, 50/50 acetonitrile/water) were introduced into the source using PANI-coated emitters, which were positioned $\sim 2 \mathrm{~cm}$ from the inlet of the mass spectrometer. The ion source voltage used was $5500 \mathrm{~V}$ for nanoESI.

\section{Results and Discussion}

The charge state distribution of any ESI mass spectrum can be evaluated by the weighted average charge state (ACS), given by eq 2 [49]:

$$
\mathrm{ACS}=\sum N_{i} I_{i} / \sum I_{i}
$$

where $N_{i}$ is the number of charges on each peak representing the intact molecule, and $I_{i}$ is the absolute intensity of each peak.

\section{Cytochrome c with Different Redox Reagents}

Figure 1 shows that when $10 \mu \mathrm{M}$ cytochrome $c$ was mixed with $100 \mu \mathrm{M}$ redox reagent solutions, the multiple charge state distribution of the protein shifted to one centered at lower positive mode charge states. Initially, in the 50/50 acetonitrile/water solvent, the most in- 


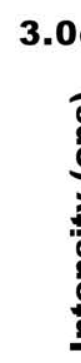

5
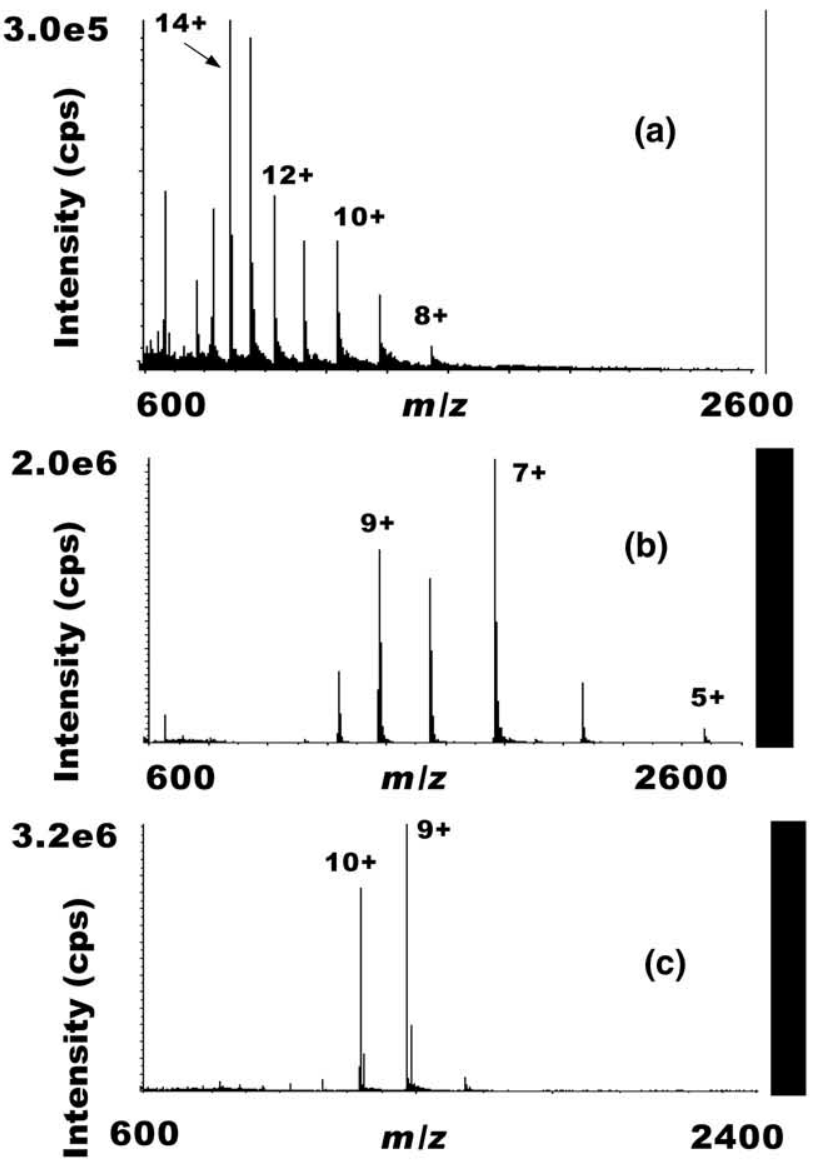
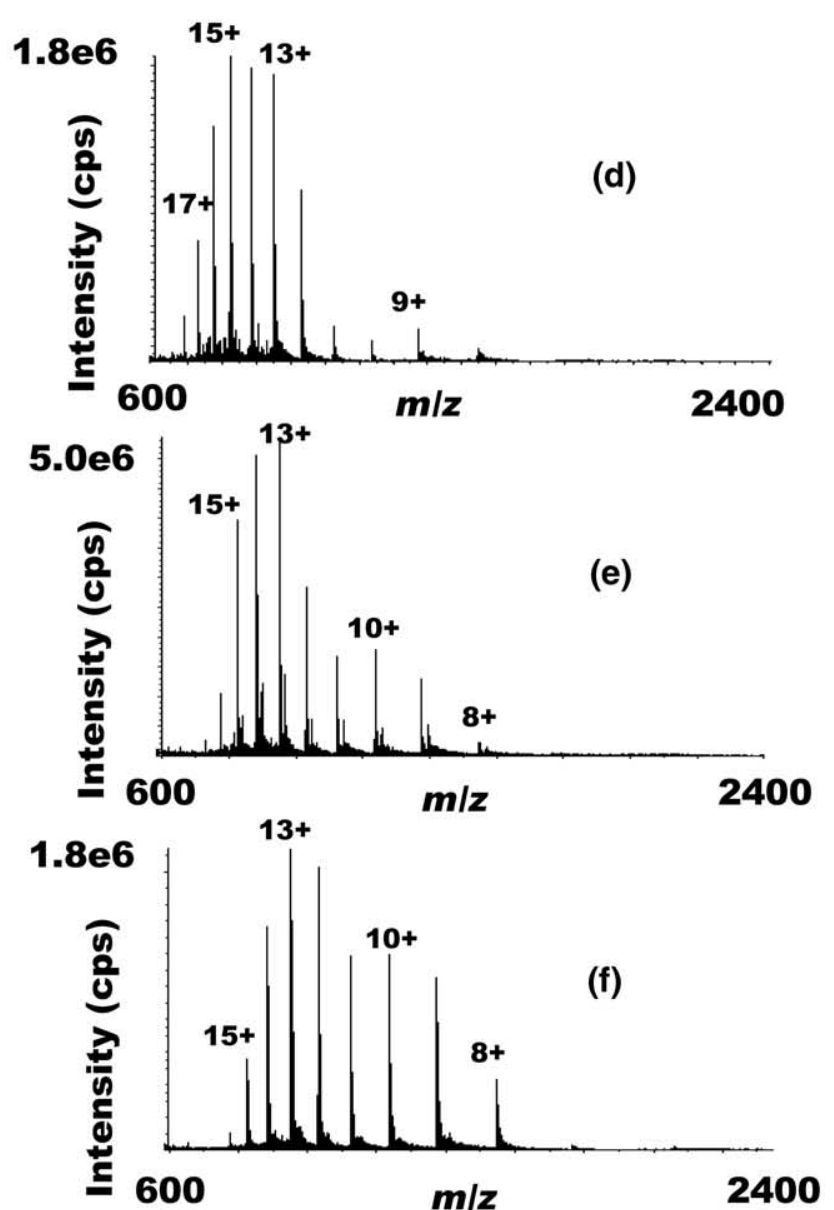

Figure 1. Nanospray mass spectra of (a) $10 \mu \mathrm{M}$ cytochrome $c$, (b) $10 \mu \mathrm{M}$ cytochrome $c$ with $100 \mu \mathrm{M}$ 1,4-benzoquinone, (c) $10 \mu \mathrm{M}$ cytochrome $c$ with $100 \mu \mathrm{M}$ quinhydrone, (d) $10 \mu \mathrm{M}$ cytochrome $c$ with 100 $\mu \mathrm{M}$ hydroquinone, (e) $10 \mu \mathrm{M}$ cytochrome $c$ with $100 \mu \mathrm{M}$ TCNQ, (f) $10 \mu \mathrm{M}$ cytochrome $c$ with $100 \mu \mathrm{M}$ ascorbic acid.

tense charge state of the cytochrome $c$ was +14 . Adding quinhydrone shifted the most intense peak to the +9 charge state, while adding 1,4-benzoquinone shifted the most intense peak even farther to the +7 charge state. Upon addition of TCNQ, hydroquinone, or ascorbic acid, the most intense charge state changed only slightly, all to the +13 charge state. Based on this observation alone, 1,4-benzoquinone appears to be the most effective of these redox reagents in shifting the charge states of cytochrome $c$ to the lower values. In addition, determination of ACS supports the hypothesis that 1,4-benzoquinone is the most effective redox reagent in lowering the observed charge state distribution. Compared to the ACS of $10 \mu \mathrm{M}$ cytochrome $c$ in $50 / 50$ acetonitrile/water, which was 14.25 (Table 1 ), the ACS of $10 \mu \mathrm{M}$ cytochrome $c$ with quinhydrone and 1,4-benzoquinone was reduced considerably, to 7.10 for 1,4-benzoquinone and to 9.43 for quinhydrone.

In Figure 2a, far UV CD reveals only small differences in ellipticities for cytochrome $c$ between aqueous and 50/50 acetonitrile/water solvent systems. Thus, the secondary structure of cytochrome $c$ is little perturbed by the addition of acetonitrile. This result is completely consistent with earlier $\mathrm{CD}$ measurements of cytochrome $c$ in $30 \%$ acetonitrile solution, where only $8 \%$ loss of $\alpha$-helical content was observed [54]. Figure $2 \mathrm{~b}$ indicates how much conformational change cytochrome $c$ undergoes upon addition of redox reagent. Addition of 1,4benzoquinone results in virtually no change to the far UV CD spectra. For quinhydrone and hydroquinone, the negative features at 208 and $222 \mathrm{~nm}$ are only slightly more intense, indicating the secondary structure is maintained. Clearly the addition of redox reagent does not have a significant effect on the conformation of cytochrome $c$; thus, conformational effects can be ruled

Table 1. ACS of cytochrome $c$ and cytochrome $c$ with different redox reagents

\begin{tabular}{lr}
\hline Sample & ACS \\
\hline \hline $10 \mu \mathrm{M}$ cytochrome $c$ & 14.25 \\
$10 \mu \mathrm{M}$ cytochrome $c$ with $100 \mu \mathrm{M}$ 1,4-benzoquinone & 7.10 \\
$10 \mu \mathrm{M}$ cytochrome $c$ with $100 \mu \mathrm{M}$ quinhydrone & 9.43 \\
$10 \mu \mathrm{M}$ cytochrome $c$ with $100 \mu \mathrm{M}$ hydroquinone & 14.04 \\
$10 \mu \mathrm{M}$ cytochrome $c$ with $100 \mu \mathrm{M}$ TCNO & 12.95 \\
$10 \mu \mathrm{M}$ cytochrome $c$ with $100 \mu \mathrm{M}$ ascorbic acid & 11.82 \\
\hline
\end{tabular}



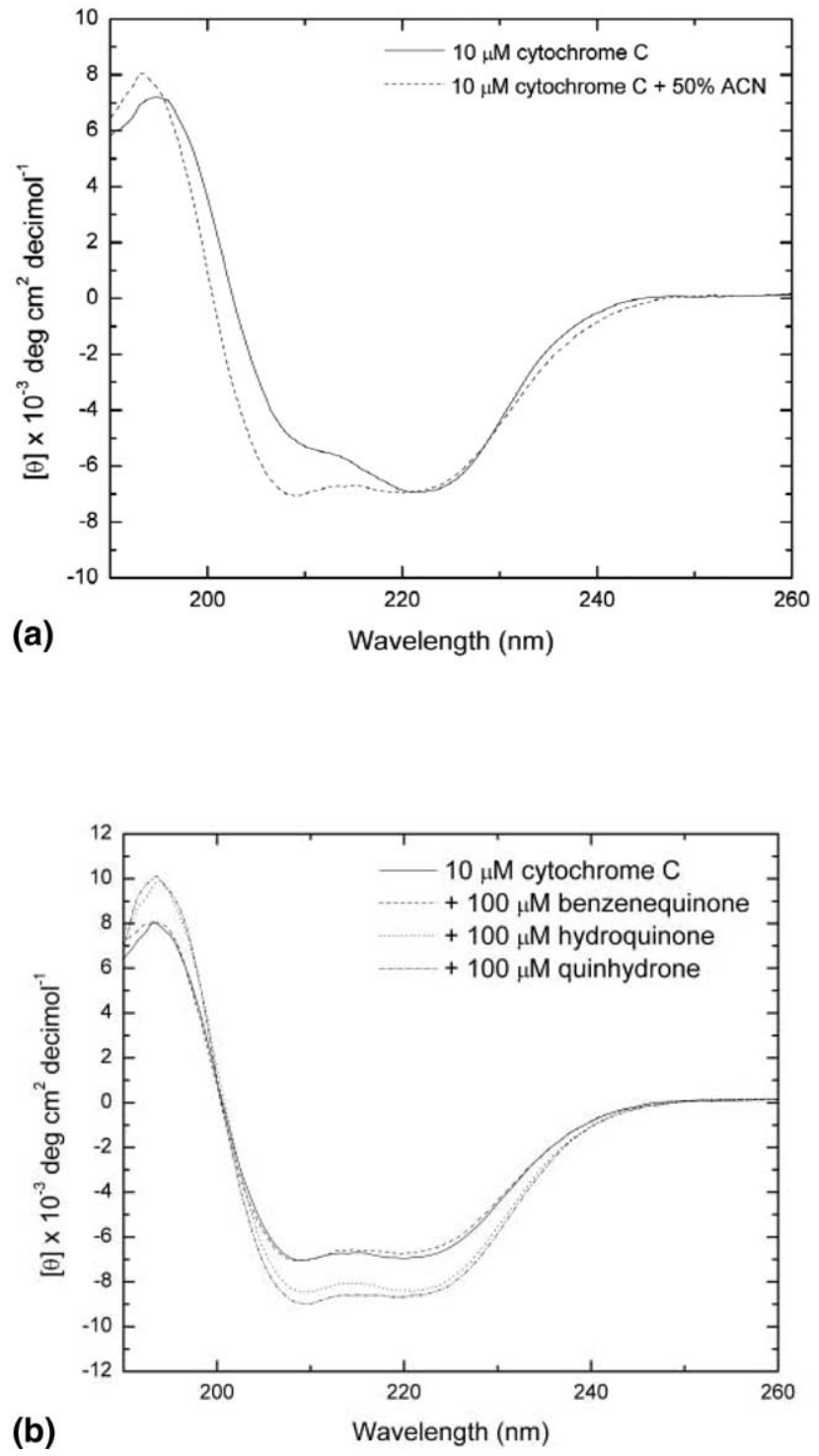

Figure 2. Far-UV CD spectra of cytochrome $c(10 \mu \mathrm{M})$ : (a) Aqueous versus 50/50 acetonitrile/water, and (b) with the addition of $100 \mu \mathrm{M}$ of a redox reagent (1,4-benzenequinone, hydroquinone, or quinhydrone), 50/50 acetonitrile/water solution.

out as the source of the shift in ACS distribution observed in Figure 1.

The differing results for 1,4-benzoquinone (Q), hydroquinone $\left(\mathrm{H}_{2} \mathrm{Q}\right)$, and quinhydrone $\left(\mathrm{Q}_{2} \mathrm{Q}\right)$ appear to be dictated by solution-phase, and not gas-phase, behavior. For example, the gas-phase basicity of hydroquinone was recently determined to be $808.4 \mathrm{~kJ} / \mathrm{mol}$ [55] while that of 1,4-benzoquinone is slightly lower at $799.1 \mathrm{~kJ} / \mathrm{mol}$ [56]. If gas-phase basicity dominated the charge reduction phenomenon, then cytochrome $c$ admixed with hydroquinone would be expected to have a lower ACS distribution than cytochrome $c$ admixed with 1,4-benzoquinone. As shown in Table 1, the opposite is true, with cytochrome $c$ showing negligible ACS shift upon addition of hydroquinone (14.25 to 14.04). Thus, gas-phase basicity of the redox reagents is not the likely explanation for these results; however, they can be rationalized in terms of the redox half reaction involving these species. First, we note that quinhydrone is a 1:1 adduct of quinone and hydroquinone that is largely dissociated in aqueous solutions into an equimolar mixture of quinone and p-hydroquinone.

$$
\mathrm{Q} \cdot \mathrm{H}_{2} \mathrm{Q}=\mathrm{H}_{2} \mathrm{Q}+\mathrm{Q}
$$

Consequently, the redox properties of this system are described by the reversible half cell reaction

$$
\mathrm{Q}+2 \mathrm{H}^{+}+2 \mathrm{e}=\mathrm{H}_{2} \mathrm{Q}
$$

In a solution containing only $\mathrm{Q}$, the reversible potential is very positive because no $\mathrm{H}_{2} \mathrm{Q}$ is present, i.e., such a quinone solution is strongly oxidizing and may extract protons from a species, $\mathrm{H}_{\mathrm{m}} \mathrm{X}^{\mathrm{p}+}$, containing protons in the course of a net redox process. Because equal concentrations of $\mathrm{Q}$ and $\mathrm{H}_{2} \mathrm{Q}$ exist in a quinhydrone solution, it adopts the reversible standard potential of redox half cell. The latter potential is much less positive and thus much less oxidizing than in a pure quinone solution. Consequently, the analyte species (cytochrome $c$ ) is likely to be depronated to a lesser extent.

In order for the complete redox process to occur, a source/sink of electrons is required. Several possibilities exist. For example, the electron source might be the negative high voltage counter electrode while the analyte species $\mathrm{H}_{\mathrm{m}} \mathrm{X}^{\mathrm{p}+}$ (e.g., cytochrome $c$ ) formed in the absence of quinone merely serves as a source of protons. In another scenario, the analyte species $\mathrm{H}_{\mathrm{m}} \mathrm{X}^{\mathrm{p}+}$ could be redox active, and thus could be oxidized (lose electrons) and also transfer protons so that the net decrease in its positive charge will be greater than that due solely to proton loss. In this case, such product species would be evident from the $m / z$ spectrum. Highresolution mass spectrometry experiments are underway to determine whether electron transfer makes any significant contribution to the charge state reduction.

Mixing of $10 \mu \mathrm{M}$ cytochrome $c$ with the redox reagents hydroquinone $(\mathrm{ACS}=14.04)$, TCNQ $(\mathrm{ACS}=$ 12.95 ), or ascorbic acid (ACS $=11.82$ ) resulted in much smaller changes in ACS, which was anticipated. Hydroquinone is the reduced form of 1,4-benzoquinone, thus a proton transfer mechanism from cytochrome $c$ to hydroquinone would be precluded. This would also be expected for ascorbic acid, which is in its reduced form. TCNQ is an electron acceptor (oxidizing agent) and thus would not be expected to reduce the ACS.

\section{Different Concentrations of Cytochrome c with Quinhydrone}

Solutions containing $100 \mu \mathrm{M}$ quinhydrone and varying concentrations of cytochrome $c$, from $30 \mu \mathrm{M}$ down to $100 \mathrm{nM}$ were studied. The breadth of the charge state distribution of cytochrome $c$ was reduced in all cases when it was admixed with quinhydrone as compared to 

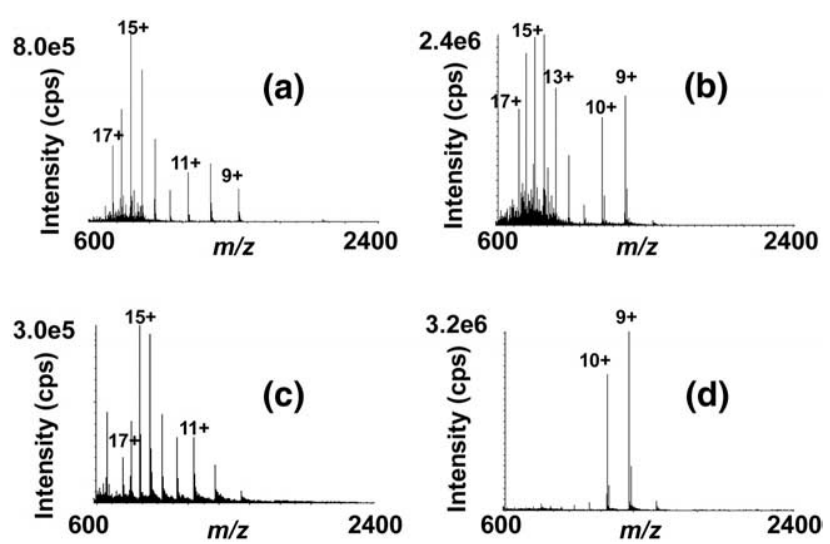

Figure 3. Nanospray mass spectra of (a) $30 \mu \mathrm{M}$ cytochrome $c$, (b) $30 \mu \mathrm{M}$ cytochrome $c$ with $100 \mu \mathrm{M}$ quinhydrone, (c) $10 \mu \mathrm{M}$ cytochrome $c$, (d) $10 \mu \mathrm{M}$ cytochrome $c$ with $100 \mu \mathrm{M}$ quinhydrone.

the control (no redox reagent); the maximum populated charge state shifted to lower values in all cases. In addition, the detection limit was improved by concentrating the signal into fewer charge states.

Figure 3 compares the mass spectra of $30 \mu \mathrm{M}$ and $10 \mu \mathrm{M}$ cytochrome $c$ without quinhydrone (Figure $3 a$ and $c$ ) and with quinhydrone (Figure $3 b$ and $d$ ). Panels a and c show that the charge state distribution was relatively insensitive to the cytochrome $c$ concentration, in the absence of redox reagent. However, this was not the case when cytochrome $c$ was mixed with quinhydrone. When mixed with quinhydrone, the higher charge state distributions shifted to more compressed lower charge state distributions, i.e., it became narrower (b and $d$ ). Interestingly, the observed ACS of cytochrome $c$ mixed with quinhydrone was related to the quinhydrone to cytochrome $c$ molar ratio rather than concentration of cytochrome $c$ (Table 2). When the concentration of cytochrome $c$ was decreased from $20 \mu \mathrm{M}$ to $10 \mu \mathrm{M}$ (reflecting an increase in quinhydrone/cytochrome $c$ molar ratio), the ACS was reduced from 13.55 to 9.43 . These changes were readily apparent in the mass spectra. For example, when the concentration of cytochrome $c$ was decreased a factor of three from $30 \mu \mathrm{M}$ to $10 \mu \mathrm{M}$, the high charge state peaks from +17 to +12 disappeared, and the intensity of low charge state peaks $(+10,+9)$ increased dramatically. The maximum $\mathrm{S} / \mathrm{N}$ of the $+10,+9$ peaks was observed at $5 \mu \mathrm{M}$ cytochrome $c$ and $100 \mu \mathrm{M}$ quinhydrone. This is illustrated in another way in Figure 4, which shows the intensity

Table 2. ACS of different concentration cytochrome $c$ mixed with $100 \mu \mathrm{M}$ quinhydrone

\begin{tabular}{lr}
\hline Sample & ACS \\
\hline \hline $30 \mu \mathrm{M}$ cytochrome $c$ with $100 \mu \mathrm{M}$ quinhydrone & 13.53 \\
$20 \mu \mathrm{M}$ cytochrome $c$ with $100 \mu \mathrm{M}$ quinhydrone & 13.55 \\
$10 \mu \mathrm{M}$ cytochrome $c$ with $100 \mu \mathrm{M}$ quinhydrone & 9.43 \\
$5 \mu \mathrm{M}$ cytochrome $c$ with $100 \mu \mathrm{M}$ quinhydrone & 9.53 \\
$1 \mu \mathrm{M}$ cytochrome $c$ with $100 \mu \mathrm{M}$ quinhydrone & 9.65 \\
$0.5 \mu \mathrm{M}$ cytochrome $c$ with $100 \mu \mathrm{M}$ quinhydrone & 9.65 \\
\hline
\end{tabular}
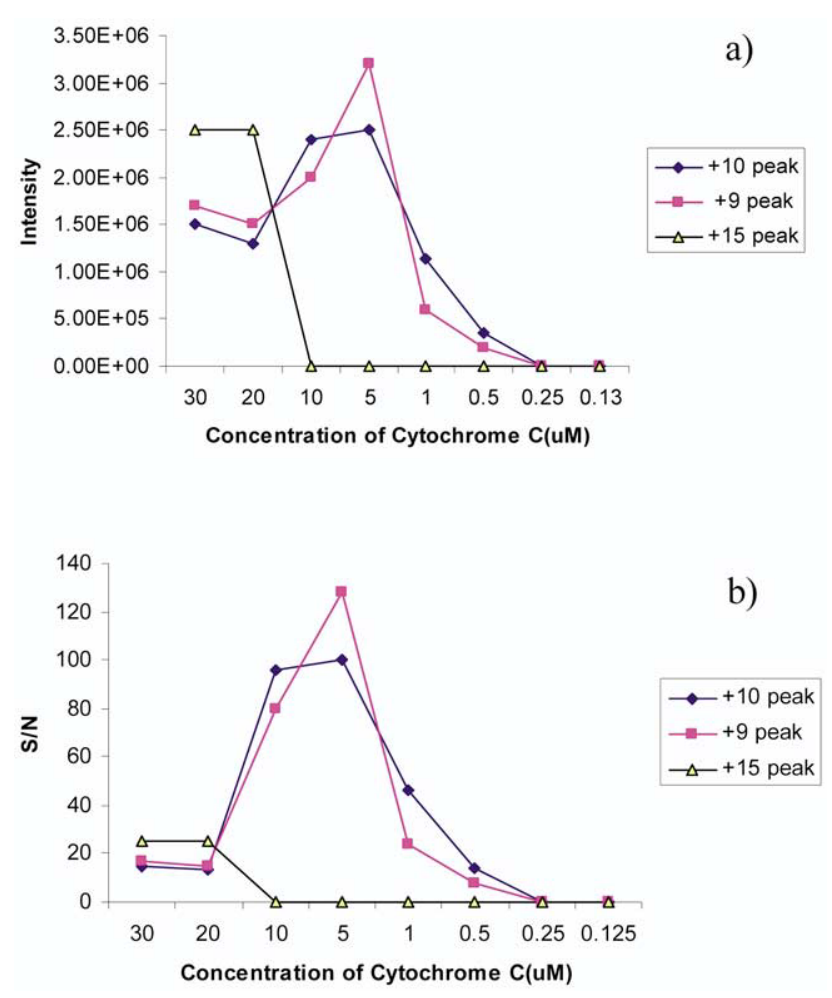

Figure 4. (a) Intensity of $+15,+10$, and +9 peak of different concentration cytochrome $c$ mixed with $100 \mu \mathrm{M}$ quinhydrone, (b) sensitivity $(\mathrm{S} / \mathrm{N})$ of $+15,+10$, and +9 peak of different concentration cytochrome $c$ mixed with $100 \mu \mathrm{M}$ quinhydrone. All were acetonitrile solutions.

changes of the $+15,+10$, and +9 peaks that accompany cytochrome $c$ concentration changes. It also shows how the sensitivity $(\mathrm{S} / \mathrm{N})$ of the $+15,+10$, and +9 peaks varies with cytochrome $c$ concentration.

\section{Ubiquitin with Quinhydrone}

Figure 5 shows the results obtained for ubiquitin upon adding the redox reagent quinhydrone. The ACS before and after addition of quinhydrone are given in Table 3. The result was analogous to that observed for cytochrome $c$. When $100 \mu \mathrm{M}$ quinhydrone was mixed with $10 \mu \mathrm{M}$ ubiquitin, the ACS of ubiquitin was reduced from 13.63 to 7.60. In Figure 6a, far UV CD reveals only small differences in ellipticities for ubiquitin between aqueous and 50/50 acetonitrile/water solvent systems,

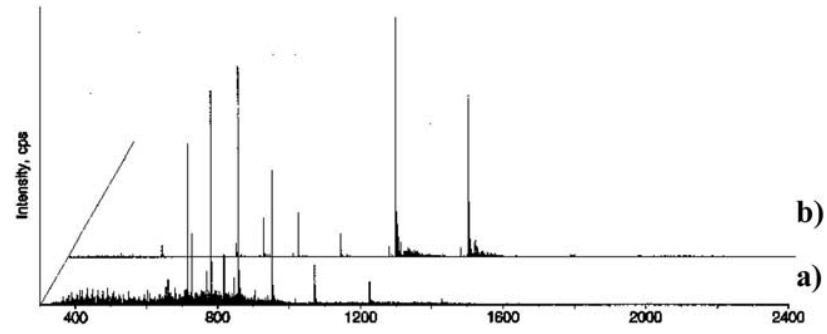

Figure 5. Nanospray mass spectra of (a) $10 \mu \mathrm{M}$ ubiquitin, and (b) $10 \mu \mathrm{M}$ ubiquitin with $100 \mu \mathrm{M}$ quinhydrone. 
Table 3. ACS of ubiquitin and different concentration ubiquitin mixed with quinhydrone

\begin{tabular}{lr}
\hline Sample & ACS \\
\hline \hline $10 \mu \mathrm{M}$ ubiquitin & 13.63 \\
$10 \mu \mathrm{M}$ ubiquitin with $100 \mu \mathrm{M}$ quinhydrone & 7.60
\end{tabular}

indicating that the secondary structure of ubiquitin is not disturbed by introduction into acetonitrile, and upon addition of any of the redox reagents, this secondary structure is largely retained, as indicated by the far UV CD spectra in Figure 6b. Thus, protein unfolding is unlikely to account for the charge state reduction observed for ubiquitin upon addition of quinhydrone; like cytochrome $c$, the charge state reduction of ubiquitin also seems likely to be induced by the redox reagent.
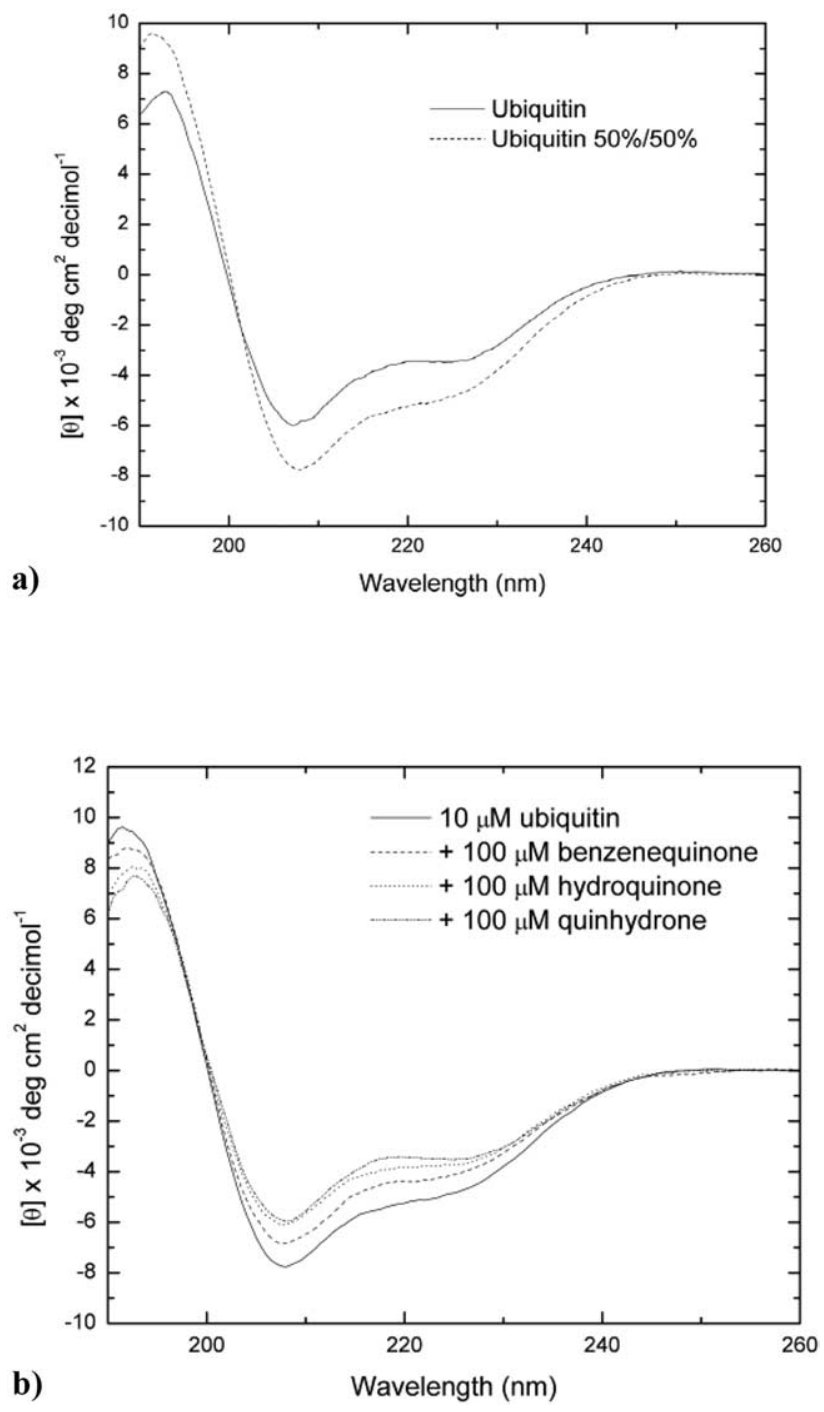

Figure 6. Far-UV CD spectra of ubiquitin $(10 \mu \mathrm{M})$ : (a) Aqueous versus 50/50 acetonitrile/water, and (b) with the addition of 100 $\mu \mathrm{M}$ of a redox reagent (1,4-benzenequinone, hydroquinone, or quinhydrone), 50/50 acetonitrile/water solution.

\section{Conclusions}

Different redox reagents have different influences on the charge state distribution of protein. For example, 1,4-benzoquinone can shift the multiple charge state distribution of proteins such as cytochrome $c$ from higher charge states to lower charge states and the weighed average charge state can also be reduced. Quinhydrone also shifts the charge state distribution of cytochrome $c$ and reduces the average charge state, although it does not decrease the charge state as much as 1,4-benzoquinone does. The charge state distribution of ubiquitin was shifted from higher charge states to lower ones and the ACS was reduced when ubiquitin was mixed with quinhydrone. However, for the redox reagents hydroquinone, TCNQ, and ascorbic acid, smaller effects were noted on the ACS of cytochrome $c$; these were consistent with their redox properties. Further research will investigate what roles proton-transfer and/or electron-transfer play. The present low-resolution mass spectrometry does not permit us to distinguish between "charge transfer" mechanisms, though with sufficiently high field electrospray ionization Fourier-transform mass spectrometry the issue may be resolved [57].

\section{Acknowledgments}

The authors gratefully acknowledge Eric J. Herbert for help in collecting the circular dichroism spectra. Funding from the National Science Foundation (CHE-0094961, TDW) and Nanogenesys, Inc. (through subcontract provided by NIH SBIR grant R43-RR16399-01 and R44-RR16399-03 to Marie A. Moy) was greatly appreciated.

\section{References}

1. Aebersold, R.; Goodlet, D. R. Mass Spectrometry in Proteomics. Chem. Rev. 2001, 101, 269-295.

2. Pierce, W. M.; Cai, J. Applications of Mass Spectrometry in Proteomics. In Proteomics in Nephrology, Thongboonkerd, V.; Klein, J.B., Eds.; Karger: Basel, Switzerland, 2004; pp 40-58.

3. Fenn, J. B.; Mann, M.; Meng, C. K.; Wong, S. F.; Whitehouse, C. M. Electrospray Ionization for Mass Spectrometry of Large Biomolecules. Science 1989, 246, 64-71.

4. Bacher, G.; Korner, R.; Atrih, A.; Foster, S. J.; Roepstorff, P.; Allmaier, G. Negative and Positive Ion Matrix-Assisted Laser Desorption/Ionization Time-of-Flight Mass Spectrometry and Positive Ion Nano-Electrospray Ionization Quadrupole Ion Trap Mass Spectrometry of Peptidoglycan Fragments Isolated from Various Bacillus Species. J. Mass Spectrom. 2001, 36, 124-139.

5. Cheng, X.; Bakhtiar, R.; Van Orden, S.; Smith, R. D. ChargeState Shifting of Individual Multiply-Charged Ions of Bovine Albumin Dimer and Molecular Weight Determination Using an Individual-Ion Approach. Anal. Chem. 1994, 66, 2084-2087.

6. Mann, M.; Meng, C. K.; Fenn, J. B. Interpreting Mass Spectra of Multiply Charged Ions. Anal. Chem. 1989, 61, 1702-1708.

7. Loo, J. A.; Edmonds, C. G.; Udseth, H. R.; Smith, R. D. Effect of Reducing Disulfide-Containing Proteins on Electrospray Ionization Mass-Spectra. Anal. Chem. 1990, 62, 693-698. 
8. Katta, V.; Chowdhury, S. K.; Chait, B. T. Electrospray Ionization-a New Tool for the Analysis of Ionic Transition-Metal Complexes. J. Am. Chem. Soc. 1990, 112, 5348-5349.

9. Mirza, U. A.; Cohen, S. L.; Chait, B. T. Heat-Induced Conformational-Changes in Proteins Studied by Electrospray Ionization Mass-Spectrometry. Anal. Chem. 1993, 65, 1-6.

10. Leblanc, J. C. Y.; Beuchemin, D.; Siu, K. W. M.; Guevremont, R.; Berman, S. S. Thermal-Denaturation of Some Proteins and Its Effect on Their Electrospray Mass-Spectra. Org. Mass Spectrom. 1991, 26, 831-839.

11. Downard, K. M.; Biemann, K. Charging Behavior of Highly Basic Peptides During Electrospray Ionization-a Predilection for Protons. Int. J. Mass Spectrom. Ion Processes 1995, 148, 191-202.

12. Fenn, J. B. Ion Formation from Charged Droplets: Roles of Geometry, Energy, and Time. J. Am. Soc. Mass Spectrom. 1993, $4,524-535$.

13. Wang, G.; Cole, R. B. Mechanistic Interpretation of the Dependence of Charge-State Distributions on Analyte Concentrations in Electrospray-Ionization Mass-Spectrometry. Anal. Chem. 1995, 67, 2892-2900.

14. Chowdhury, S. K.; Katta, V.; Chait, B. T. Differences in Charge States of Electrosprayed Native and Denatured Proteins. J. Am. Chem. Soc. 1990, 112, 9012-9013.

15. Smith, R. D.; Loo, J. A.; Edmonds, C. G.; Barinaga, C. J.; Udseth, H. R. New Developments in Biochemical Mass Spectrometry: Electrospray Ionization. Anal. Chem. 1990, 62, 882899.

16. Ikonomou, M. G.; Blades, A. T.; Kebarle, P. Investigations of the Electrospray Interface for Liquid Chromatography/Mass Spectrometry. Anal. Chem. 1990, 62, 957-967.

17. McLuckey, S. A.; Van Berkel, G. J.; Glish, G. L. Reactions of Dimethylamine with Multiply Charged Ions of Cytochrome $c$. J. Am. Chem. Soc. 1990, 112, 5668-5670.

18. Smith, R. D.; Loo, J. A.; Edmonds, C. C.; Baringa, C. J.; Udseth, H. R. New Developments in Biochemical Mass-SpectrometryElectrospray Ionization. Anal. Chem. 1990, 62, 882-899.

19. McLuckey, S. A.; Glish, G. L.; Van Berkel, G. J. Charge Determination of Product Ions Formed from CollisionInduced Dissociation of Multiply Protonated Molecules via Ion/Molecule Reactions. Anal. Chem. 1991, 63, 1971-1978.

20. Winger, B. E.; Light-Wahl, K. J.; Smith, R. D. Gas-Phase Proton-Transfer Reactions Involving Multiply Charged Cytochrome $c$ Ions and Water Under Thermal Conditions. J. Am. Soc. Mass Spectrom. 1992, 3, 624-630.

21. Ogorozalek-Loo, R. R.; Loo, J. A.; Udseth, H. R.; Fulton, J. L.; Smith, R. D. Protein Structural Effects in Gas Phase Ion/ Molecule Reactions with Diethylamine. Rapid Commun. Mass Spectrom. 1992, 6, 159-165.

22. Cassady, C. J.; Wronka, J.; Kruppa, G. H.; Laukien, F. H. Deprotonation Reactions of Multiply Protonated Ubiquitin Ions. Rapid Commun. Mass Spectrom. 1994, 8, 394-400.

23. Leblanc, J. C. Y.; Wang, J. Y.; Guevremont, R.; Siu, K. W. M. Electrospray Mass-Spectra of Protein Cations Formed in Basic Solutions. Org. Mass Spectrom. 1994, 29, 587-593.

24. Gronert, S. Determining the Gas-Phase Properties and Reactivities of Multiply Charged Ions. J. Mass Spectrom. 1999, 34, 787-796.

25. Amad, M. H.; Cech, N. B.; Jackson, G. S.; Enke, C. G. Importance of Gas-Phase Proton Affinities in Determining the Electrospray Ionization Response for Analytes and Solvents. J. Mass Spectrom. 2000, 35, 784-789.

26. Loo, J. A.; Udseth, H. R.; Smith, R. D. Collisional Effects on the Charge Distribution of Ions from Large Molecules Formed by Electrospray-Ionization Mass Spectrometry. Rapid Commun. Mass Spectrom. 1988, 2, 207-210.
27. Guevremont, R.; Siu, K. W. M.; Leblanc, J. C. Y.; Berman, S. S. Were the Electrospray Mass-Spectra of Proteins Related to Their Aqueous-Solution Chemistry. J. Am. Soc. Mass Spectrom. 1992, 3, 216-224.

28. Kelly, M. A.; Vestling, M. M.; Fenselau, C. C.; Smith, P. B. Electrospray Analysis of Proteins-a Comparison of PositiveIon and Negative-Ion Mass-Spectra at High and Low pH. Org. Mass Spectrom. 1992, 27, 1143-1147.

29. Wang, G. D.; Cole, R. B. Disparity Between Solution-Phase Equilibria and Charge-State Distributions in Positive-Ion Electrospray Mass Spectrometry. Org. Mass Spectrom. 1994, 29, 419-427.

30. Konermann, L.; Silva, E. A.; Sogbein, O. F. Electrochemically Induced $\mathrm{pH}$ Changes Resulting in Protein Unfolding in the Ion Source of an Electrospray Mass Spectrometer. Anal. Chem. 2001, 73, 4836-4844.

31. Cole, R. B.; Harrata, A. K. Charge-State Distribution and Electric-Discharge Suppression in Negative-Ion Electrospray Mass Spectrometry Using Chlorinated Solvents. Rapid Commun. Mass Spectrom. 1992, 6, 536-539.

32. Cole, R. B.; Harrata, A. K. Solvent Effect on Analyte ChargeState, Signal Intensity, and Stability in Negative-Ion Electrospray Mass-Spectrometry-Implications for the Mechanism of Negative-Ion Formation. J. Am. Soc. Mass Spectrom. 1993, 4, 546-556.

33. Wang, G. D.; Cole, R. B. Effect of Solution Ionic Strength on Analyte Charge-State Distributions in Positive and Negative Ion Electrospray Mass Spectrometry. Anal. Chem. 1994, 66, 3702-3708.

34. Ashton, D. S.; Beddell, C. R.; Cooper, D. J.; Green, B. N.; Oliver, R. W.; Welham, K. J. On the purity of 3X-recrystallized bovine alpha-chymotrypsin. Biochem. Biophys. Res. Commun. 1993, 192, 75-81.

35. Schmidt, A.; Bahr, U.; Karas, M. Influence of Pressure in the First Pumping Stage on Analyte Desolvation and Fragmentation in Nano-ESI MS. Anal. Chem. 2001, 73, 6040-6046.

36. Mirza, U. A.; Chait, B. T. Effects of Anions on the Positive-Ion Electrospray-Ionization Mass Spectra of Peptides and Proteins. Anal. Chem. 1994, 66, 2898-2904.

37. Verkerk, U. H.; Peschke, M.; Kebarle, P. Effect of Buffer Cations and of $\mathrm{H} 3 \mathrm{O}+$ on the Charge States of Native Proteins. Significance to Determinations of Stability Constants of Protein Complexes. J. Mass Spectrom. 2003, 38, 618-631.

38. Stephenson, J. L., Jr.; McLuckey, S. A. Charge Reduction of Oligonucleotide Anions via Gas-Phase Electron Transfer to Xenon Cations. Rapid Commun. Mass Spectrom. 1997, 11, 875880.

39. Stephenson, J. L., Jr.; McLuckey, S. A. Charge Manipulation for Improved Mass Determination of High-Mass Species and Mixture Components by Electrospray Mass Spectrometry. J. Mass Spectrom. 1998, 33, 664-672.

40. Stephenson, J. L., Jr.; McLuckey, S. A. Simplification of Product Ion Spectra Derived from Multiply Charged Parent Ions via Ion/Ion Chemistry. Anal. Chem. 1998, 70, 3533-3544.

41. Stephenson, J. L., Jr.; McLuckey, S. A. Ion/Ion Reactions for Oligopeptide Mixture Analysis: Application to Mixtures Comprised of 0.5-100 kDa Components. J. Am. Soc. Mass Spectrom. $1998,9,585-596$.

42. Stephenson, J. L.; McLuckey, S. A.; Reid, G. E.; Wells, J. M.; Bundy, J. L. Ion/Ion Chemistry as a Top-Down Approach for Protein Analysis. Curr. Opin. Biotechnol. 2002, 13, 57-64.

43. Scalf, M.; Westphall, M. S.; Krause, J.; Kaufman, S. L.; Smith, L. M. Controlling Charge States of Large Ions. Science 1999, 283, 194-197.

44. Scalf, M.; Westphall, M. S.; Smith, L. M. Charge Reduction Electrospray Mass Spectrometry. Anal. Chem. 2000, 72, 52-60. 
45. Ebeling, D. D.; Westphall, M. S.; Scalf, M.; Smith, L. M. Corona Discharge in Charge Reduction Electrospray Mass Spectrometry. Anal. Chem. 2000, 72, 5158-5161.

46. Ebeling, D. D.; Westphall, M. S.; Scalf, M.; Smith, L. M. A Cylindrical Capacitor Ionization Source: Droplet Generation and Controlled Charge Reduction for Mass Spectrometry. Rapid Commun. Mass Spectrom. 2001, 15, 401-405.

47. Fierens, C.; Stockl, D.; Thienpont, L. M.; De Leenheer, A. P. A Convenient Method for the Generation of Negative and Positive Electrospray Ionization Mass Spectra of Proteins by Gas-Phase Admission of Volatile Bases and Acids via the Nebulizing Gas. Rapid Commun. Mass Spectrom. 2001, 15, 451-453.

48. Wilm, M. S.; Mann, M. Electrospray and Taylor Cone Theory, Dole's Beam of Macromolecules at Last? Int. J. Mass Spectrom. Ion Processes 1994, 136, 167-180.

49. Li, Y.; Pozniak, B. P.; Cole, R. B. Mapping of Potential Gradients Within the Electrospray Emitter. Anal. Chem. 2003, 75, 6987-6994.

50. White, T. P.; Wood, T. D. A Unique Alternative Emitter for Low-Flow Electrospray Ionization. Am. Biotechnol. Lab. 2002, $20,16,18$
51. White, T. P.; Wood, T. D. Reproducibility in Fabrication and Analytical Performance of Polyaniline-Coated Nanoelectrospray Emitters. Anal. Chem. 2003, 75, 3328-3333.

52. Maziarz, E. P., III; Lorenz, S. A.; White, T. P.; Wood, T. D. Polyaniline: A Conductive Polymer Coating for Durable Nanospray Emitters. J. Am. Soc. Mass. Spectrom. 2000, 11, 659-663.

53. Smith, D. R.; Sagerman, G.; Wood, T. D. Design and Development of an Interchangeable Nano-Microelectrospray Source for a Quadrupole Mass Spectrometer. Rev. Sci. Instrum. 2003, $74,4474-4477$.

54. Sivakolundu, S. G.; Mabrouk, P. A. Cytochrome $c$ Structure and Redox Function in Mixed Solvents are Determined by the Dielectric Constant. J. Am. Chem. Soc. 2000, 122, 1513-1521.

55. Bouchoux, G.; Defaye, D.; McMahon, T.; Likholyot, A.; Mo, O.; Yanez, M. Structural and Energetic Aspects of the Protonation of Phenol, Catechol, Resorcinol, and Hydroquinone. Chem. Eur. J. 2002, 8, 2900-2909.

56. Hunter, E. P. L.; Lias, S. G. Evaluated Gas Phase Basicities and Proton Affinities of Molecules: An update. J. Phys. Chem. Ref. Data 1998, 27, 413-656.

57. McLafferty, F. W. High-Resolution Tandem FT Mass Spectrometry above $10 \mathrm{kDa}$. Acc. Chem. Res. 1994, 27, 379-386. 